\title{
Teachers' Perspectives on the Intertwining of Tangible and Digital Modes of Activity with a Drawing Robot for Geometry
}

\author{
Anna E. Baccaglini-Frank ${ }^{1, *(\mathbb{D})}$, George Santi ${ }^{2}$, Agnese Del Zozzo ${ }^{3}$ and Eric Frank ${ }^{4}$ \\ 1 Mathematics Department, University of Pisa, 56127 Pisa, Italy \\ 2 Faculty of Education, Free University of Bolzano-Bozen, 39042 Bressanone, Italy; gesanti@unibz.it \\ 3 Mathematics Department, University of Trento, 38123 Trento, Italy; agnese.delzozzo@unitn.it \\ 4 Department of Physiology, Tufts School of Medicine, Boston, MA 02111, USA; eric.frank@tufts.edu \\ * Correspondence: anna.baccaglinifrank@unipi.it
}

Received: 25 November 2020; Accepted: 16 December 2020; Published: 18 December 2020

\begin{abstract}
The GeomBot is a drawing robot that combines the well-known strengths and opportunities offered by Scratch with those of Papert's original robotic drawing-turtle. In this study we look at the GeomBot as a physical programmable artifact around which action research with a group of teachers and a researcher was carried out with the aim of designing, implementing and discussing geometry activities for primary school classes. The aim of this article is to investigate teachers' positioning and perspectives with respect to the activities and the educational environment emerging around the Geombot in the action research. The action research meetings between September 2018 and June 2019 included nine primary school teachers from seven different Italian schools, who met regularly with the first author. After the design and experimentation sessions, in June 2019, the teachers shared their experiences during a final meeting and group discussion guided by the first author. The data collected from the teachers were analyzed using cultural categories from the Semiotic Systems of Cultural Signification, theorized by the Theory of Objectification, to identify the most significant features defining the teachers' perspectives and identity. The seven emergent features cover teachers' positioning with respect to: forms of rationality and language and languages: sensuous cognition and the use of ideal and material semiotic resources; accepted teaching practices, problems and situations; mathematical knowledge; the conception of the student; social interaction and forms of rationality; ethical issues; technology.
\end{abstract}

Keywords: action research; drawing robot; GeomBot; geometry teaching; scratch-based programming

\section{Introduction: The GeomBot as an Artifact for the Teaching and Learning of Geometry}

This study lies at the crossroads of using artifacts in mathematics teaching and learning, embodied cognition in mathematics and action research. At their meeting point lies the artifact in focus: a drawing robot called the GeomBot, that was specifically designed and constructed by two of the authors for the teaching and learning of geometry at primary school.

There is a long tradition in mathematics education research concerning the implementation of material artifacts for mathematics teaching-learning activities in the classroom (e.g., [1]). In our opinion, a turning point in the study of the role of artifacts in processes of teaching and learning mathematics has been marked by research concerning semiotics. Indeed, the link between the use of artifacts and mathematical teaching and learning was established when studies in semiotics acknowledged what Arzarello [2] calls outer enlargement. He refers to Vygotskian sociocultural theories in mathematics education that allowed for the broadening of the notion of sign beyond Fregean 
classical semiotics to include gestures, objects, tools, linguistic devices etc. Among the most important examples of outer enlargement are Arzarello's semiotic bundle [2], Bartolini Bussi and Mariotti's Theory of Semiotic Mediation [1], and Radford's Theory of Objectification [3]. Using artifacts in mathematical activities entails a multimodal approach to cognition that intertwines senses, emotions, material objects, bodily movements and the conceptual realm. Therefore, in order to fully understand where to position these in students' learning, we need to connect semiotic approaches with theories of embodied cognition in mathematics [4].

The GeomBot, the specific artifact introduced to the teachers in the action research activities we analyze in this study, together with the programming language used to give it commands from a computer, intertwines physical and digital modes of activity. On the one hand, the unique set of characteristics of the GeomBot, explicitly designed for the teaching of geometry, are new to the literature, as we will discuss. On the other hand, such characteristics make designing and implementing didactical activities with the GeomBot a potentially rich and novel experience even for teachers who have previously used digital artifacts in their classrooms, even other robots (we note that according to the definition proposed by Calmet, Hirtzig and Wilgenbus [5], a robot should contain sensors; the current prototype of the GeomBot does not have sensors, although they could easily be added. We choose to still refer to the GeomBot as a robot similarly to what is done in educational research.).

As we will point out in the next section, while there has been quite a bit of research on learning mathematics by programming physical or digital artifacts that respond to commands, much less attention has been paid to the teachers' perspective and to how their sensitivity towards specific design features of an artifact like the GeomBot may develop through many months of action research. Therefore, we chose to focus this study on how the GeomBot's design may shape teachers' interactions, identifying the most significant features that they noticed during an action research project that lasted 10 months long and involved nine primary school teachers and one researcher.

We will present our study as follows. Section 2 has two subsections: in Section 2.1 the empirical background is described, in Section 2.2 we outline the theoretical framework, and we present our research question; in Section 3 we describe materials and methods of our research; in Section 4 we present our results, organized in seven features, in order to answer to our research question; finally, Section 5 concludes the work reviewing the key points in the Discussion, and in Section 6 we present limitations and future perspectives of our work.

\section{Empirical Background and Theoretical Foundation}

To properly contextualize the GeomBot, we first present the empirical context related to programmable physical artifacts along with a brief presentation of the literature in mathematics education related to their study, so as to identify our potential contribution. Next, we present the theoretical foundations that we will refer to from Section 3 onwards, both for the description of the GeomBot's design and for the analysis of the data collected during the project. The research question, formulated with respect to these foundations, concludes Section 2.

\subsection{Empirical Background}

GeomBot's ancestor is Papert's drawing turtle shown in Figure 1. Papert saw his drawing turtle and the Logo environment used to program it as a microworld, an informal environment in which knowledge, applied to a specific discipline (in our case geometry), is incorporated. In this way, the objects and the modes of mediation of the microworld offer the user a direct encounter with the underlying mathematical objects. In many cases the interaction between the student and the microworld occurs in the school setting, and the role of the teacher is key, especially in the design of the activities. 


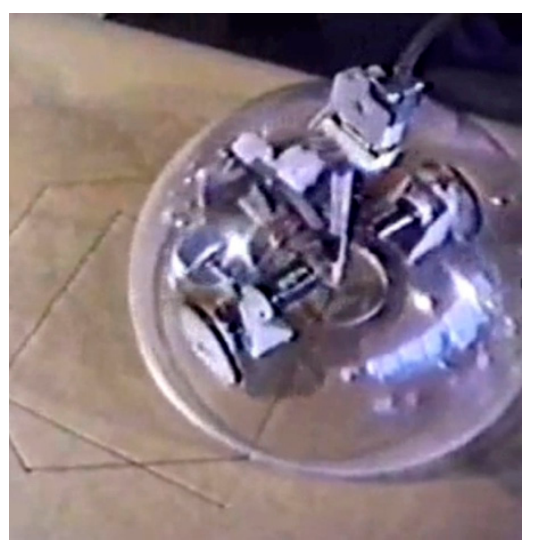

Figure 1. Papert's drawing turtle that was programmed using Logo; a screenshot from the YouTube video available at: https://youtu.be/BTd3N5Oj2jk.

Numerous studies in the 80 s and 90 s inspired by Papert's pioneering work $[6,7]$ suggest educational benefits of learning geometry through Logo and Logo-based computer software [8-14]. This literature includes case studies about how the programming of Papert's robotic turtle can enhance the learning of mathematics, especially in the context of special education-e.g., $[15,16]$. More recently, studies have been carried out with young learners (ages 4-7) programming digital toys such as the Bee-bot, a very simple version of the original Logo robot turtle-e.g., [17-20]. These studies suggest that the experience of programming a robot that leaves a visible trace (we note that the Bee-bot does not have a marker-holder, but the teacher can "follow it" with a marker, to leave the trace of its path on paper, as was done in [21]) as it moves can be very powerful in fostering young students' productions of narratives and a rich variety of written and verbal signs-e.g., [21,22]. These experiences can be exploited by the teacher to foster and enhance mathematical learning. Indeed, in previous studies that focused specifically on achieving the transfer of learning from the Logo environment to Euclidean Geometry the role of the teacher has been recognized as fundamental—e.g., [14]. Moreover, being able to see the code in the form of blocks, as offered in Scratch or ScratchMaths, affords new representations (along with the drawings) of the geometrical objects and fosters further learning opportunities [23]. Benton, Hoyles, Kalas and Noss [23] identified a strong relationship between learning to program and learning to express mathematical ideas through programming in older students (ages 9-11).

In spite of Papert's original idea and in spite of the line of research outlined above, most of the activities with robots proposed in classrooms currently aim at introducing "programming" or "coding" per se, and the robots end up being "little more than toys made to drive to and fro or side to side without really providing an opportunity for any scientific exploration and learning" [24]. We believe that this is in part due to the fact that these robotic toys are not designed with an explicit intention for them to become tools for mathematical learning, in which coding is not introduced per se (we note that an acritical use of the word "coding", can hide some too simplistic ideas of what computational thinking and computer science education are; to deepen this delicate issue, from the perspective of computer science education, we recommend reading [25]), but as a canvas for expressing mathematical ideas, such as algorithms, equations, as well as geometrical properties of a figure. Furthermore, in spite of the acknowledgement of the key role of the teacher, to the best of our knowledge, there seem to be many more studies related to the students' learning than to teachers' perspectives on didactical practices in mathematics enhanced by physical programmable artifacts. Though studies like that of Reich-Stiebert, Eyssel and Khanlari [26,27] provide a focus on the teachers' point of view in using robots in teaching and learning, these are not contextualized in the field of mathematics education.

To sum up, our study should provide contributions in two directions. First, the design of the GeomBot itself should stand out as an example of a physical programmable artifact explicitly for the teaching and learning of geometry that combines the well-known potential of Papert's turtle with the 
benefits of visual block programming languages. Second, the study contributes to bridging the gap in the literature on teachers' perspectives in approaching a new artifact such as the GeomBot.

\subsection{Theoretical Foundation and Research Question}

This study intertwines different dimensions embedded in a specific theoretical perspective. We will follow a sociocultural and historical approach drawing upon the Theory of Objectification [3] to look at the implementation of processes of mathematical thinking and learning fostered by using a drawing robot and the teachers' noticing of specific features of their work with this drawing robot.

\subsubsection{Theory of Objectification and Sensuous Cognition}

The Theory of Objectification is one of the most solid and acknowledged theoretical stances in mathematics education. Based on Vygotsky's and Leont'ev Cultural Historical Activity Theory [28,29], the Theory of Objectification goes beyond rationalist or individualist views of cognition reconciling the subjective and the objective, the sensual and the conceptual, the ideal and material. Cognition, revisited from a non-mentalist standpoint, is conceived as a sociocultural and historical practice, namely a praxis cogitans. Radford points out that "thinking is considered to be a mediated reflection in accordance with the form or mode of the activity of individuals" [3] (p. 218, emphasis in original). Conceptual objects, thinking, learning and meaning in mathematics are intertwined in reflexive mediated activity.

- Activity refers to the individual and social agency towards shared goals, significant problems, operations, labor etc.

- Reflexivity refers to the dialectical movement of the individual consciousness between his personal thinking, interpretations, emotions and feelings, perceptions and cultural-historical, marked by symbolic superstructures-in the terminology of the Theory of Objectification, Semiotic Systems of Cultural Signification [3] - that include systems of beliefs, systems of truth, forms of rationality, methods of inquiry, acceptable forms of knowledge, social rules, epistemology and ontology of mathematics etc. [3].

- Mediation refers to the role of artifacts in carrying out the praxis cogitans. In a Vygotskian sense, they are constitutive and consubstantial to thinking since they allow us to carry out activity. They are not mere aids to thinking but they shape the socio-cultural space, the Territory of Artifactual Thought [3] in which cognition occurs. They include a wide arsenal of semiotic resources ranging from material objects, gestures and bodily movements to icons, diagrams, natural language and symbolic language. The territory of Artifactual Thought molds the way we act according to the cultural and historical meanings they condense and are endowed with.

Learning is a specific praxis cogitans that Radford [3] terms a process of objectification. In its etymological meaning it refers to the process that allows the student to notice, find and encounter the cultural object. The artifacts that accomplish the objectification processes are called semiotic means of objectification [30] and they cover the whole range of ideal and material resources mentioned above. In Radford's [30] (p. 41, emphasis in original) words:

"These objects, tools, linguistic devices, and signs that individuals intentionally use in social meaning-making processes to achieve a stable form of awareness, to make apparent their intentions, and to carry out their actions to attain the goal of their activities, I call semiotic means of objectification."

The Theory of Objectification can be set into the strand of embodied cognition in mathematics-for an overview we refer the reader to [4]. Radford [4,31,32], resorting to a dialectic materialistic stance, conceives embodiment as a sensuous cognition, that is, a multimodal sentient form of responding to the world sprouting from cultural and historical activity. Cultural and historical activity intertwines, in sensuous cognition, senses, feelings, materiality, and the conceptual realm. The multimodality of the individual's response intertwines the manifold possibilities of human perceptions (sight, touch, sensorimotor activity, feelings) with the modes of activity realized by the variety of semiotic means of 
objectification that cover the whole spectrum of human experiences, ideal and material, sensual and conceptual, subjective and objective.

The materiality of cognition is not something subsumed in the mind to acquire the nature of a concept, but the material is consubstantial to the conceptual. Senses, feelings, materiality and the conceptual realm culturally and socially develop into what [31] terms "highly sensitive cultural objects-theoreticians" [31] (p. 353, emphasis in original), in which the material and the ideal are tuned into the objectification of mathematical generality. The multimodal nature of cognition allows us to outline levels of generality [30] at which the student objectifies the mathematical concept. The level of generality specifies the blending of ideal and material in the process of objectification, according to the artifacts that realize the process of objectification:

- Factual generalization -characterized by perception, feelings, movement, spatial and temporal elements of the students' physical environment—is accounted for mainly by gestures, bodily movements, material objects and deictic and generative use of natural language.

- Contextual generalization intertwines material perception, movement and feelings with a new perceptual field in which emergent objects are detached from mediated sensory perception. Students start introducing more ideal semiotic means of objectification, such as new linguistic terms, natural language and the first elements of symbolic language.

- In symbolic generalizations, perception is no longer embedded or related to a concrete space-time context but in a new abstract and relational "space" where mathematical activity is carried out mainly by symbolic language.

\subsubsection{Teachers' Action Research as a Process of Subjectification}

The Theory of Objectification offers an effective lens to interpret teachers' collaboration [33]; it allows for the broadening of the notion of Community of Practice [34] that is a cornerstone in the action research experience. In particular, we want to analyze the teachers' positionings and perspectives with respect to technology and geometrical teaching and learning as they engage in collaborative activities with the drawing robot. We look at such a positioning through the lens of subjectification [35], the counterpart of objectification, related to the production of subjectivities as they engage in the reflexive mediated activity. If objectification pertains to the process of knowing, subjectification pertains to the process of becoming, that is, the changes and development of the individual. The Theory of Objectification outlines a dialectical co-production between individuals and their cultural and historical reality. Radford [35] (p. 43) conceives the individual as:

"[ ... ] an entity in flux, in perpetual becoming—an entity who, through practical activity (like play) is continuously inscribing herself in the social world and, in doing so, she is continuously produced and co-producing herself within the limits and possibilities of her culture."

We would like to point out two fundamental features mentioned in the above quotation that define both the production of subjectivities (subjectification) and its entangled counterpart, that is, the production of knowledge (objectification): agency and the cultural-historical context. Agency and the cultural-historical context also live in a dialectical relationship where they continuously co-produce themselves. The cultural-historical context defines who we are, how we conceive of ourselves and how others conceive of us, the "fabric of our subjectivity" [35] (p. 46), the space, the constraints and the forms of our agentic maneuvering. This generative capacity of culture is termed by Radford [35] as being. If, on the one hand, we are existentially determined and generated by our cultural-historical context, on the other hand we hold a reflexive relationship with our cultural context, which means that "we react agentically to such a context" [35] (p. 4). Being materialized by the individual's deeds is termed by Radford [35] a process of becoming.

As we mentioned in the previous section, the cultural-historical context unfolds as a symbolic superstructure, the Semiotic Systems of Cultural Signification: a network of distinctive traits that makes up the fabric of a culture and its society. They emerge from individuals' reflective activity and they amount to dynamic systems, which are at the basis of a society's modes of meaning production. 
Radford [3,35] singles out some of the fundamental Semiotic Systems of Cultural Signification that characterize mathematical thinking and learning. For the scope of our study we have focused on:

A. mathematical knowledge: geometry

B. language and languages: multimodality and semiotic resources

C. accepted teaching practices, problems and situations

D. conception of the student: affection, modes of learning

E. forms of rationality: sensuous cognition

F. social interaction

G. ethics

H. the role of technology in mathematical thinking and learning:

We are interested in analyzing subjectification as the critical positioning of the teachers involved in the action research as they discover new possibilities of moving, acting, feeling, perceiving, and thinking in the educational socio-cultural space that develops around the use of the drawing robot.

\subsubsection{Research Question}

In this study we address the following research question:

How do teachers position themselves with respect to the educational space emerging from designing and implementing classroom activities with the GeomBot?

In particular, what is the teachers' positioning with respect to the role of the GeomBot in fostering students' affective engagement, social interaction, cognition, geometrical knowledge and teaching practices?

\section{Material and Methods}

This section is comprised of several parts: in the first we present the participants; in the second a presentation of the study design is given; in the third we describe the design of the physical programmable artifact we consider, the GeomBot, outlining its potential to realize mathematics generalization as a form of sensuous cognition; in the fourth we present the implementations details of the action research around the GeomBot; and in the fifth we introduce the data collected.

\subsection{Partecipants}

Nine primary school teachers from the Group of Research and Experimentation in Mathematics Education of the Department of Mathematics (GRSDM) of the University of Pisa participated in this action research project, together with the first author of the paper, a mathematics education researcher. All the teachers had been members of the GRSDM for at least two years and had signed informed consent forms for all research carried out within their collaboration with the University. Moreover, many of the schools in which these teachers work have specific informed consent forms approved by their administration, which are signed each year by the parents of the students in their classes. In this paper we only include images from classrooms where such consent forms had been signed. The nine participants, all female, were from 7 different schools; and two pairs of them, Monica and Lynn, and Corinna and Lisa, worked at the same primary school building but at different grade levels (all teachers' names used in this paper are pseudonyms). All the participants were experienced teachers: they had been teaching in primary schools for between 10 and 35 years, though not all of them had been teaching mathematics for their whole career. Finally, five of the teachers were used to using interactive white boards regularly (Monica, Lynn, Fiona, Mary and Rebecca) and three of them had in previous cycles (so not with the children involved in this project) worked with robots such as the Bee-bot or the Pro-bot (Lynn, Fiona and Mary). The teaching habits of the nine teachers in this study were well-known to the researcher involved in the meetings with the teachers, because she had conducted other mathematics education projects with these teachers over the past 
three years. The teachers' teaching habits in geometry involved the use of paper-and-pencil approaches, frequently accompanied by other physical experiences like paper folding or painting, and sometimes (though rarely) an interactive dynamic geometry applet.

\subsection{Design of the Study}

The data collected for this paper come from an action research project [36] that took place over an entire academic year between September 2018 and June 2019 through the different phases that are detailed in Section 3.4. The activities were carried out in the form of teachers' collaboration within a community of practice characterized by: a common domain of interest; social interaction between the members of the community; and a common practice. We conceived practice as a mediated reflexive activity realized with GeomBot. The purpose of such action research was to collaborate on the design, implementation and discussion of activities for teaching geometry with the GeomBot in primary school grades. All the teachers had been introduced to the GeomBot during the previous academic year and some of them had even used it in their classes for some pilot activities. The group used an online moodle platform to share information and materials. The experimental classes where the teachers implemented the activities were chosen based on teachers' availability and desire to participate, and with a preference towards those with cases of students with mathematics learning difficulties. Indeed, in each classroom in which the designed activities were implemented, there was at least one student with some form of mathematical learning difficulty-either reported by the teachers or certified in a clinical diagnosis of a specific learning disorder. These criteria also let us gather information on inclusive aspects of teaching and learning with the GeomBot.

\subsection{Materials}

The GeomBot uses an Arduino chip to activate two independent stepper motors connected to its wheels, which can be activated at the same or different speeds and in either direction, a buzzer, and LED lights that signal the different commands as they are executed. A marker-holder allows a marker to be placed between the wheels so that a trace mark is left on a sheet of paper (or whiteboard) on the floor, as shown in Figure 2. Most physical parts of the GeomBot are designed using 3D modelling software (SketchUp and OpenSCAD) and printed using a 3D printer. The wireless communicator (lower left-hand side of Figure 2a) uses a serial port connection on stable frequencies that do not interfere with one another when more than one robot is used in the same classroom. Finally, unlike other rechargeable robots that stop in the middle of an activity and need to be recharged, the GeomBot uses batteries that can be changed on the spot whenever they run down.

The following physical properties of the GeomBot's design make evident how the robot physically draws-a feature that can be exploited in multimodal activities entangling various geometrical meanings with physical sensorial experiences. Rubber rings around its wheels touch the ground in a small area (evoking a point); the drawing marker is inserted into a prism with a square base and the drawing tip of the marker comes out exactly at the square's center, touching the ground at the midpoint between the points of contact between the wheels and the ground, which is also the pivot point around which the GeomBot rotates in the basic "turn" commands (evoking the vertex of an angle) (Figure 2b). These features are designed so that the GeomBot's multimodality can be exploited to foster the generation of signs in relation with the geometrical meanings of point, distance, and angle. Moreover, the GeomBot can also be told to turn around one of its wheels (see the PIVOT commands in Table 2), in which case the marker rotates around the wheel that does not move (fixed point) drawing a circle or an arc (evoking the locus of points with a certain distance from a given fixed one).

So on the one hand, the physical properties mentioned above play a key role in materializing thought. Firstly, we note that the term "material" introduced in the Theory of Objectification has to be understood in the sense of dialectic materialism. Objects are not just lifeless "things", instead they are culturally related to the subject's praxis cogitans that endows them always with new life. On the other hand, we highlighted how the material properties of the GeomBot-intertwined with the ideal 
ones-are designed to foster cultural development of the student's senses into theoreticians that allow them to notice and become aware of geometric concepts. These are not given per se but they are a cultural and historical way of perceiving, moving, feeling and thinking. Therefore, the design of the physical properties of GeomBot accomplishes the unity of the sensual and conceptual, of the material and ideal, of the subject and object.
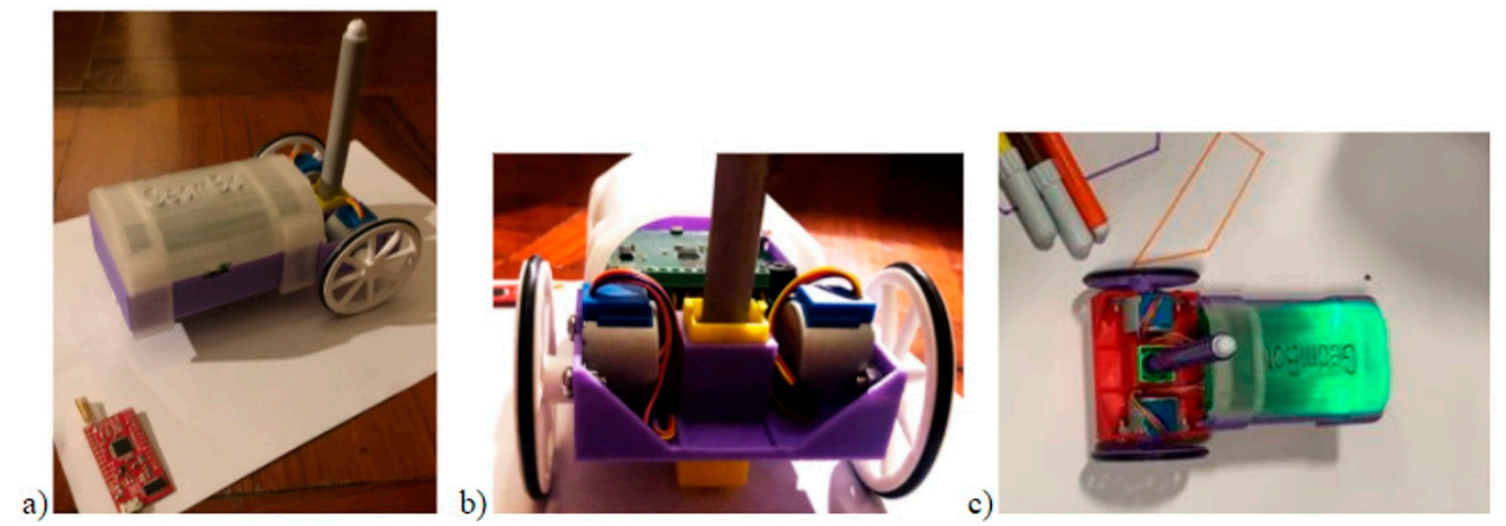

Figure 2. (a) The GeomBot and its wifi transmitter to be connected to a computer; (b) back view of the GeomBot showing the marker-holder with a marker touching the paper; (c) top view of the GeomBot in action.

To program the GeomBot and make it move and draw, we designed command blocks in a Scratch-based language (Tables 1 and 2). These command blocks are available in addition to Scratch's default set. The first set of blocks (Table 1) is the simplest, and is analogous to the commands that can be given to simple robots like the Bee-bot through push buttons. This analogy allows for meanings developed by many Italian students in preschool and kindergarten to be transferred to the GeomBot context in first grade. Moreover, the fact that when talking to the GeomBot, the commands, which are virtual blocks that can be manipulated on the screen, can foster contextual generalization: now sequences of commands are objects that can be manipulated and talked about, allowing their relationships with the movements and the drawn out figures to become more explicit and detached from immediate sensory perception.

Table 1. First set of blocks designed for Grade 1 students.

\begin{tabular}{ccc}
\hline Blocks & Command & What the GeomBot Does \\
\hline PASSO $\uparrow$ & step forward & moves $15 \mathrm{~cm}$ forward, flashes both LEDs green \\
\hline PASSO $\downarrow$ & step backward & $\begin{array}{c}\text { moves } 15 \mathrm{~cm} \text { backward, flashes both LEDs red } \\
\text { GIRO Sf }\end{array}$ \\
\hline GIRO D 7 & $90^{\circ}$ turn counterclockwise & $\begin{array}{c}\text { rotates } 90^{\circ} \text { counterclockwise around the pen, } \\
\text { flashes left LED blue }\end{array}$ \\
& $90^{\circ}$ turn clockwise & $\begin{array}{c}\text { rotates } 90^{\circ} \text { clockwise around the pen, } \\
\text { flashes right LED blue }\end{array}$ \\
\hline
\end{tabular}

Activities based on geometry can be designed to create the opportunity for students to gradually discover and make use of increasingly complex commands (such as those included in Table 2) with parameters that lead to new forms of movement and drawing. Indeed, these new commands can be used to explore new and more general ways-up to pre-symbolic generalizations-to describe, 
notice and characterize the geometrical notions on which their teachers choose to focus during the proposed activities.

Table 2. Additional blocks we have designed in the Scratch-based environment.

\begin{tabular}{|c|c|}
\hline Blocks & What the GeomBot Does \\
\hline PASSO $+15^{\circ} \mathrm{cm}$ & $\begin{array}{l}\text { moves forward any number of } \mathrm{cm} \text { (input from dropdown menu } \\
\text { or manual) }\end{array}$ \\
\hline PASSO $+15 \mathrm{~cm}$ & moves backward any number of $\mathrm{cm}$ \\
\hline GIRO S $6^{9} 90^{\circ}$ & rotates counterclockwise around the pen any number of degrees \\
\hline GIRO D $\rightarrow 90^{\circ}{ }^{\circ}$ & rotates clockwise around the pen any number of degrees \\
\hline PASSO $\uparrow \div 15 \div \mathrm{cm}$ & $\begin{array}{l}\text { moves forward or backward (1st parameter) any number of } \mathrm{cm} \\
\text { (2nd parameter) }\end{array}$ \\
\hline GIRO $\because 90^{\circ}$ & $\begin{array}{l}\text { rotates clockwise or counterclockwise (1st parameter) around the pen } \\
\text { any number of degrees (2nd parameter) }\end{array}$ \\
\hline PIVOT(ruota s) $\checkmark 180^{\circ}$ & $\begin{array}{c}\text { rotates counterclockwise around left wheel any number of degrees } \\
\text { (there are } 3 \text { other PIVOT commands: the } 4 \text { commands allow rotations in } \\
\text { both directions and around either wheel) }\end{array}$ \\
\hline ARCO $\because 90^{\circ}$ RA & $\begin{array}{l}\text { moves along an arc clockwise or counterclockwise (1st parameter) of } \\
\text { any number of degrees (2nd parameter) and any radius (3rd parameter) }\end{array}$ \\
\hline
\end{tabular}

We now provide an example on how the GeomBot has the potential to realize multimodal reflexive activities, thus including, in addition to the material properties of the artifact, ideal semiotic means of objectification. This potentially allows students to gradually move to higher levels of generalizations, towards what, in the light of the Theory of Objectification, we can call sensuous generalization. Let us consider the sequence in Figure 3. The same sequence allows the drawing of any rectangle with one fixed dimension (of $15 \mathrm{~cm}$-"PASSO"), including a square (when the parameters of "PASSO with a parameter" are set to 15 as shown). Focusing on semiotic characteristics of an activity with the GeomBot leading, for example, to the execution of the programmed sequence in Figure 3a. The sequence contains 4 "PASSO" (step) commands and 4 "GIRO" (turn) commands, that correspond to the 4 sides and angles of the drawn square (Figure $4 \mathrm{~b}$ ). While the turn commands are all the same-and not generalizable because the commands with no parameters were chosen - the step commands are of two different kinds and they are used in an alternating pattern. This corresponds to generalizability: what now had been drawn out as a square, could become any rectangle with two sides of $15 \mathrm{~cm}$ and two sides of different lengths, as long as the two parameters in the sequence are set to the same value. There is an intricate interconnection between the meanings of the digital signs in the programmed sequence, the physical signs produced by the GeomBot's movement on the paper, and mathematical meanings, which constitute a rich multimodal activity. Sensuous generalization is realized by moving back and forth from factual to contextual generalizations, from tangible and digital; always pursuing the unity of senses, feelings, the material and the conceptual. This potentially allows the student to live a unity of senses, movement, feelings, the material and the conceptual. 


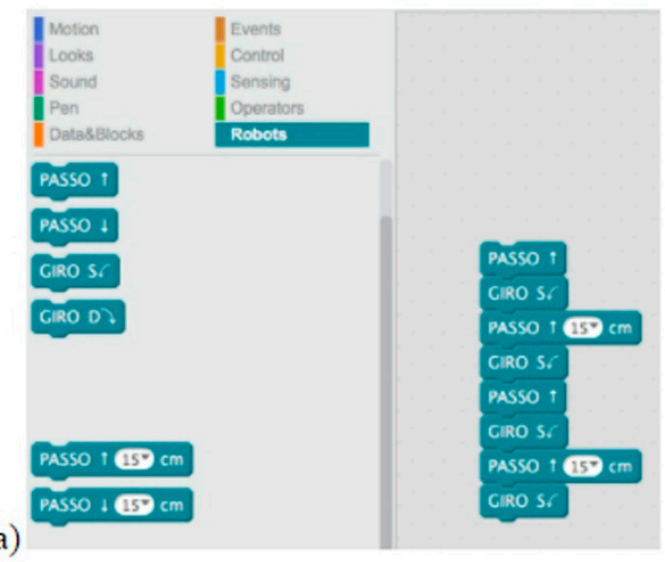

b)
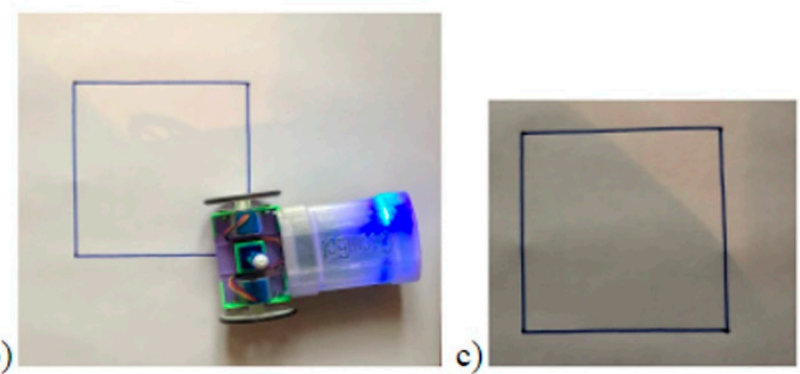

Figure 3. (a) GeomBot programming blocks (left) and a sequence for drawing any rectangle with one set dimension, including a square; (b) the GeomBot executing the sequence on paper; (c) drawing made.
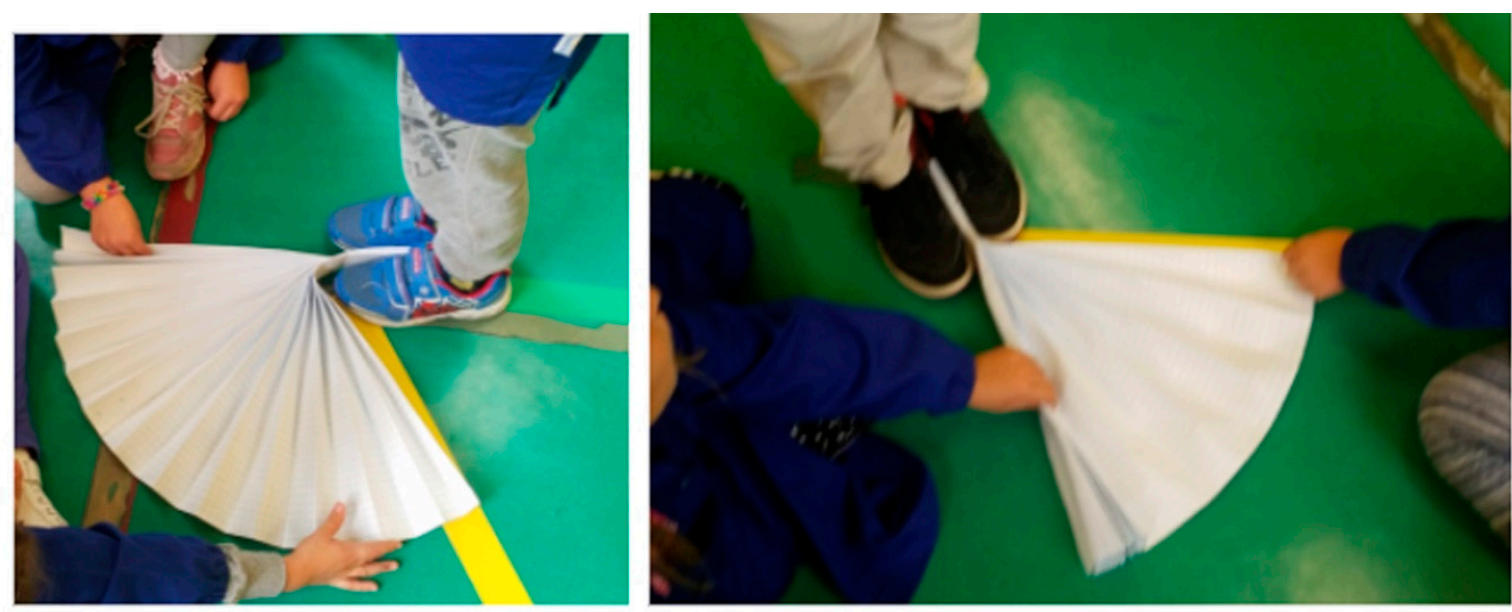

a)

b)

Figure 4. The "fan" artifact to highlight the "amount to turn" in two cases: (a) an external angle greater than a right angle; (b) an external angle that is acute. This photo comes from a presentation that a teacher Mary did during one of the monthly group sessions. Such choice suggests that the teacher felt it was important to document and share this new "fan" artifact with colleagues.

\subsection{Implementation of the Action Research around the GeomBot}

The action research comprised three different situations:

(1) a whole-group session that was carried out once a month at the University;

(2) the implementations of the activities, that teachers conducted autonomously with their selected classes between two consecutive monthly sessions;

(3) a conclusive whole-group session that was conducted by the first author. We now describe these three situations.

\subsubsection{The Monthly Group Sessions}

The first author of this paper and the nine teachers met each month for three hours at the University. During these sessions, the group worked both through collaborative design of the activities and through discussions triggered by the teachers' reports about the outcomes of their implementations. Specifically, once a certain designed activity had been implemented by one of the teachers in the classroom, this teacher would have $10 \mathrm{~min}$ at the next monthly session to share her results and observations with the others. The end of each presentation was always followed by a period of free discussion. At the 
end of the whole action research experience, the group had produced 10 activities: some of them had been implemented in the classrooms, while other activities, in line with the cyclic nature of action research, were designed as variations or additions to activities that had been implemented.

\subsubsection{The Experimental Phase between Two Consecutive Monthly Sessions}

Between two consecutive meeting sessions at the University, some teachers implemented several of the designed activities in their classrooms. During this intermediate phase, several discussions and collaborative interactions occurred, always involving a pair of people-the researcher and one or two teachers, unlike what happened during the monthly group sessions. Discussions and exchanges of ideas between the researcher and the teachers occurred via email and focused on reaching an agreement on certain details of the activities. The researcher focused on these communications, trying to outline patterns and recurring themes among different teachers. In addition to the conversations involving teachers and the researcher, interactions between teachers occurred as well, based on the affinity of interests. These teachers' interactions were assiduous and intensive. As an example, the two teachers who teach in the same building, who both admitted to having a shared fear of technology, worked on the activities themselves, meeting at school, as if they were students, before implementing them in the classrooms.

\subsubsection{The Conclusive Whole-Group Session}

The last meeting of the action research experience took place in June 2019 at the University; the nine teachers and the researcher were present. Unlike the other monthly sessions, the discussion at this meeting was triggered by the researcher who had noticed some recurring themes raised in her private sessions with teachers between the group sessions. More precisely, the discussion was initiated by the researcher like this: "Most of you spoke about how the experience with the GeomBot led you to change your ideas about the notion of angle, both as a mathematical concept and in terms of how to teach it. Could we talk about this a bit more all together?" In the second part of the last session, the teachers were invited to meet with those who had worked with the researcher on a different project and share their experiences, using PowerPoint presentations if they wished.

\subsection{Data Collected}

In order to identify the teacher's positioning with respect to the educational space reified by the GeomBot, we collected various information. We include here the list of data on which we based our analysis.

- Materials prepared and used by the teachers to present their experience to the rest of the group (slides, photos and short videos). These materials provide information both on what happened in the classes and on what the teachers considered meaningful to report and share with the rest of the group.

- The notes and the recordings collected during the discussions in the monthly sessions. These documents provide information on thoughts, questions and proposals triggered by the reports of colleagues about the implemented activities.

- The emails exchanged between teachers and the researcher. These communications provide information on the teachers' questions, doubts and fears when they were preparing the implementation of a certain activity in the classroom.

- The email descriptions and mutual requests for support of the activities, exchanged among the teachers during the experimental intermediate phases. These descriptions provide information on the collaboration modalities carried out between the teachers with common interests when they were preparing to face the implementation of certain activities in their classrooms.

- The notes and the recordings collected during the conclusive session. These documents allow us to explore in depth and to better characterize the teachers' perspective regarding the notion of 
"angle" — which was revealed to be a recurring theme among the whole action research experience for each of the nine teachers involved.

Since teachers typically report on something new to them and to their way of teaching, we reckon that the teachers' subjectification understood as their positioning in the educational space is effective to understand the impact of this distinct drawing robot on the teaching and learning of geometry in primary school. We did not consider any of the data collected to be more relevant than any other: all of it contributed to helping outline the teachers' perspective. To analyze the data, we used a thematic coding criterion based on the study's theoretical framework. We matched the data collected from the teachers with the network of symbolic superstructures that, according to Radford [3,35], characterize mathematical thinking and learning. We present the results of this analysis in the next section.

\section{Results}

In the following sections we describe the most significant positionings of the teachers that emerged from the data analysis, categorized according to the networking of the Semiotic Systems of Cultural Signification listed above (Section 2.2.2, list from A to H).

\subsection{Feature 1 (Aspects B, E). Positioning with Respect to Forms of Rationality and Language and Languages:} Sensuous Cognition and the Use of Ideal and Material Semiotic Resources

The teachers were familiar with using the body in various mathematical learning activities involving paper-and-pencil and, possibly, other physical artifacts; however, they commented on how in the activities with the GeomBot using one's body to imitate the robot's movements or to pretend to be the robot given a program was a key step in linking concrete signs (e.g., the drawn paths) to more abstract signs (e.g., the sequences programmed in the Scratch-based environment). The nature of the activities with the GeomBot fostered this in a way that was more natural than with other activities. Monica and Lynn explicitly compared the activities with the GeomBot, which they described as a "sort-of-digital tool", with those they had experienced in previous years with dynamic geometry applets (for a description of these activities see [37]): while use of the body could be fostered and exploited by the teacher in the latter context, Lynn said that with the GeomBot "the body becomes a natural and unavoidable link between the concrete and the abstract". Moreover, the teachers took advantage of the natural involvement of the body to enhance students' learning by highlighting specific gestures (like the action of opening arms and holding them parallel to the ground, with one pointing in the original direction and one opening to the direction reached at the end of a programmed rotation) or by designing new artifacts like an opening "fan" to place between students' feet to highlight the "amount to turn" (see Figure 4).

The teachers' recognition of the role of the body when using GeomBot is a key feature in order to consider it an artifact that realizes sensuous mathematical generalizations. A further strength that emerges is that the Geombot truly combines the material and the ideal, because students are able to move back and forth from the sensorimotor to the conceptual. This constitutes evidence that the levels of generalization are not compartmentalized, as unfortunately can happen when students reach higher levels of generality. Typically in algebra, we testify an "evaporation of meaning" [38] and pseudostructural approaches [39] that lead students to use symbols unrelated to any mathematical meaning. The use of other artifacts such as the opening of the arms and the "fan" (Figure 4) to objectify the angles shows Geombot's potential to attract other semiotic means of objectification.

\subsection{Feature 2 (Aspect C). Positioning with Respect to Accepted Teaching Practices, Problems and Situations:} Solving Real-Life Problems

Teachers used the words "real-life problems" to describe the kinds of activities they had experienced in their classrooms with the GeomBot, and they referred to "mathematical competence" (we note that this terminology is coherent with that used in the documents by the Italian National Institute 
for Assessment of the Educational and Professional Development System (INVALSI) which writes the Italian national assessments, inspired by the OECD competency framework; see, for example, https://www.oecd.org/careers/competency_framework_en.pdf) and "problem solving skills" to describe students' learning that they thought went beyond the construction of the mathematical knowledge described in the design of each activity. Two teachers Mary and Rebecca insisted that the GeomBot activities were "more real-life" than other activities, including those they had experienced previously with dynamic geometry. When encouraged to provide examples, the teachers noticed that the GeomBot produces "real" drawings "with few imprecisions if any at all", and that students are faced with situations in which they know where they need to get but they have not been taught a procedure to get there, which is "true problem solving" (we note that many teachers in our research group have actively participated in years of professional development at the University of Pisa under the guidance of prof. Rosetta Zan and Pietro Di Martino, who frequently quote [40] in defining a problem for a subject as a situation in which the goal is clear to the subject, but not how to achieve it). As they worked, students had to react to the feedback they received from the robot, plan again or debug, and compare what they got with what they wanted. A recurring example in the teachers' comments was related to a group activity in which students in one group had to communicate with another group to achieve the same size of the figures drawn by each other. Indeed, the teachers highlighted that such a need for communication led students to figure out useful ways of communicating.

Moreover, some teachers noticed their students' different approaches to problem solving. Although most teachers reported "trial-and-error" as the most common approach, which involved students working on one piece of a drawing at a time and responding and adapting to the GeomBot's feedback, Lynn, Mary and Fiona, with classes of Grade 4 or Grade 5 students, mentioned how students who already knew Scratch (and how to use the "repeat" command) and quickly became acquainted with the GeomBot would approach problems differently. These students would plan out the commands for the entire drawing and, if necessary, make modifications that were "more general". For example, Lynn reported to the group that a pair of students in her class wrote a program for drawing a square with sides of three steps but also with "different size squares" as shown in Figure 5a.

a)

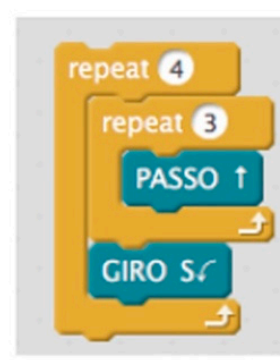

b)

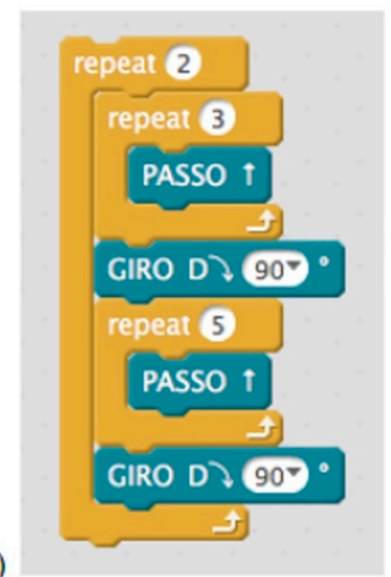

Figure 5. (a) program produced by a student of Lynn's for drawing a square with side of three steps but also "different size squares"; (b) program produced by a student of Fiona for drawing a rectangle with sides of three and five or "any rectangle", in the students' words. These screenshots come from the presentations of the teachers' reports during one of the monthly group sessions. Such choices suggest that the teachers felt it was important to document and share the code that their students wrote.

In Fiona's class, one student said she could make the GeomBot draw "any rectangle" with a program shown in Figure $5 \mathrm{~b}$ and she modified the lengths of the sides as necessary to help students in other groups. The teachers admitted to being quite pleasantly surprised by these students' ideas that exceeded their expectations. 
What the teachers call real-life problems in the frame of Theory of Objectification can be interpreted as the social and cultural dimension of reflexive mediated activity comprising thinking, teaching and learning. This is an important element to allow students to live mathematics as belonging to their personal experience, cognitively, socially and emotionally. The acquaintance of some students with effective and general solving strategies confirms that they are experiencing sensuous cognition. They are therefore able to maintain contact with meaningful mathematical activity and to move effectively across different levels of generality, in order to "geometrically" see and feel the best path towards the solution.

\subsection{Feature 3 (Aspect A). Positioning with Respect to Mathematical Knowledge: Ease in Engaging with the Specific Geometry at Stake}

The teachers' experience with the GeomBot led them to discover new ways of teaching specific geometrical notions, and, sometimes, to learn about a completely new notion. For example, for the notion of "angle", Corinna, Lisa, Lynn, Rebecca and Rita confessed to having previously defined it as "the intersection of two half-planes", or as "the part of the plane contained between two rays with a common origin". These definitions are mathematically difficult for students (and many teachers!) to understand-e.g., [41]. Moreover, all nine teachers noticed that they had previously only emphasized the "internal" angles of polygons. Instead, the activities with the GeomBot naturally led to defining angles as rotations and to seeing and talking about "internal" and "external" (meaning "supplementary", that is the angle that together with the first gives an angle of 180 degrees) angles: in a task where the drawing of a polygon is required, to get an "internal" angle of $n$ degrees the GeomBot has to be programmed to rotate by an angle of $(180-n)$ degrees. Three teachers agreed that the GeomBot provided a "friendly excuse" to go back and study or refresh important geometrical concepts.

The teachers also commented on how programming the GeomBot to draw geometrical figures exposes different geometrical properties and relationships between them with respect to those exposed by a software for dynamic geometry. This observation is perfectly in line with the analysis of the GeomBot in Section 3.3: it reinforces the crucial importance of a deep reflection upon the semiotic aspects involved in each activity. For example, Lynn reported that in her class students programmed a square by giving the GeomBot the commands "repeat 4 times: 3 steps forward, turn right" (as shown in Figure 5a), which highlights the four congruent sides and four right angles. However, the teachers noticed that in a dynamic geometry environment it is impossible to explicitly construct all four congruent sides and right angles of a square: if three consecutive congruent and perpendicular sides are constructed, the fourth side is completely defined and, when constructed, it "magically" is congruent to the other three sides and perpendicular to its two consecutive sides. These properties are derived from the other construction properties. This behavior of dynamic geometry software, that can also be exploited with older students, is too advanced for primary school children who are only beginning to discover and discuss geometrical properties of 2D figures.

In general, the teachers agreed that watching the GeomBot move (relatively slowly) and draw on paper provided greater ease for both themselves and their students to engage with the mathematics being studied. The teachers' recognition of the ease to engage with the mathematics at stake when using the GeomBot is an important finding. It confirms how, within the frame of the Theory of Objectification, artifacts are not merely inert "things", but they are bearers of cultural and historical mathematical activity that allow for the multimodal materialization of thinking in mathematics. Apparently, the teachers objectified new forms of mathematical meaning through the multimodality of the GeomBot.

\subsection{Feature 4 (Aspect D). Positioning with Respect to the Conception of the Student: Affective Dimension for Teachers and Students}

Teachers repeatedly mentioned how their students had strong positive emotional reactions to the GeomBot. These became visible on many occasions: for example, they became worried and wanted to "save GeomBot" if it was about to wander off the drawing paper or, worse, off the top of a table 
(indeed, the robot was likely to break if it fell off a table). They also wanted to design clothing for it, especially in Monica and Lynn's classes. Children used diminutive and affective forms, such as "robottino" (translated "little robot"), to refer to it; they always gave it a gender (male in seven classes and female in two); and in some cases the children insisted on giving it a name (GeomBot was the name given to it by the children in one of the classrooms). Some children interpreted GeomBot's writing as "messages" to them, especially after an introductory activity conducted in some classes that ended with the GeomBot drawing a heart to "say goodbye" (see Figure 6). Children also talked about needing to "teach him to write letters" or to "learn to draw precise figures".

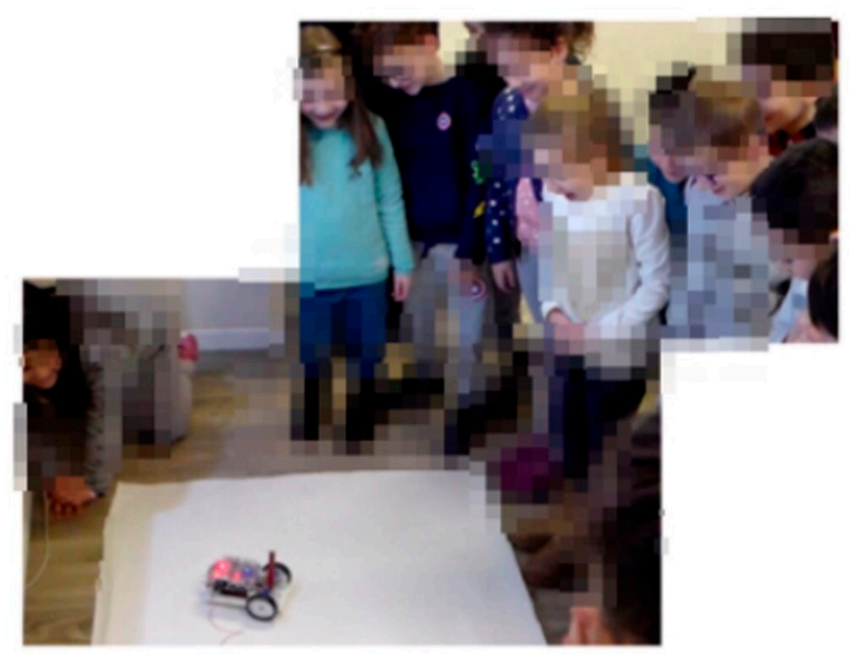

Figure 6. Children in a Grade 1 classroom extremely excited as the GeomBot said "goodbye" with a heart.

Although the teachers did not explicitly mention this, we noticed that they themselves would frequently treat the GeomBot as if it were alive, using their students' ways of talking about or to the GeomBot. They would say "bravo!" to it when it succeeded, shout "be careful!" if it was about to move off the sheet of paper, use diminutive forms like "robottino" or "poverino" (translated "little robot" and "poor little thing"), and assign it a gender (usually male, probably because "robottino" is masculine in Italian). These behaviors indicate a positive emotional connection with the GeomBot on behalf of the teachers as well.

We believe that the affective dimension related to the use of the GeomBot cannot be taken for granted. The material nature per se cannot account for triggering an affective involvement on the part of the students (and the teachers). Instead, this result can be drawn from the material nature of the artifact whose cultural, historical and social features establish in reflexive activity also an affective relationship between the individual and the object. This lack of the affective dimension would amount neither to objectification nor to sensuous cognition nor to cognition in general [41].

\subsection{Feature 5 (Aspects E, F). Positioning with Respect to Social Interaction and Forms of Rationality: Shared Reflexive Activity and Developing the Geometrical Eye}

The activities with the GeomBot in this study were designed during the action research project to involve work in small groups and whole class discussions about predicting what a programmed sequence will make the GeomBot draw and how to "fix" or debug a sequence that does not create the expected drawing (Figure 7). Students can discover that the same figure can be drawn in different ways, and thus "solved" through different sequences, which promotes problem solving skills and creativity. Students may feel empowered because their solutions do not need to be validated by the teacher; instead they can do this on their own by interacting with the GeomBot and interpreting its movements and the drawings it creates. In this sense, the use of the GeomBot in this kind of activity is extremely significant in developing the senses into geometrical theoreticians. The multimodality of the GeomBot constantly molds the students" "raw" sensuous perception into a geometric theoretical one. For example, 
predicting what a programmed sequence will make the GeomBot draw requires the student to see a figure or a path that is not present in his/her space-time perception but can be accounted for in the geometrical one, a geometrical perception that $\mathrm{s} / \mathrm{he}$ has built in previous activities or that $\mathrm{s} / \mathrm{he}$ will build by comparing what $\mathrm{s} /$ he predicted with what the robot actually draws. When a programmed sequence of commands (a set of blocks on the computer screen) is clicked, the students can see the robot move as it executes the programs and traces them out on large sheets of paper or on a whiteboard on the floor (Figure 7b). Finally, the teachers noticed how the GeomBot would enhance social interaction, a constitutive key feature of reflexive mediated activity. Amongst the several possibilities of joint action most teachers asked students to work on sequences of commands in small groups and then, one at a time, to come program their sequences on a screen visible to the whole class, to collectively generate meanings, compare and share Scratch sequences, and discuss the resulting physical drawing on paper.

a)

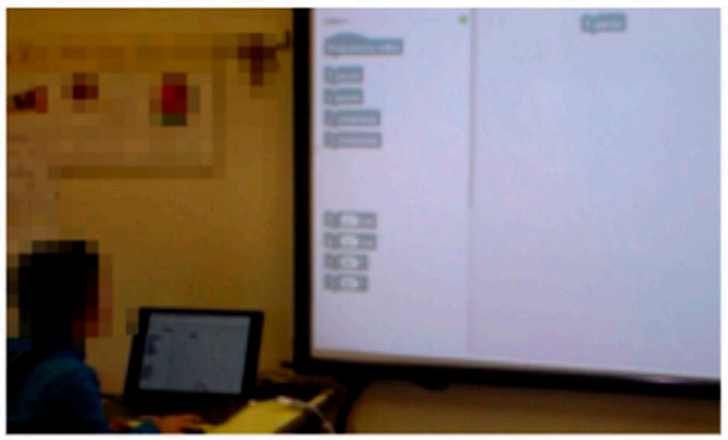

b)

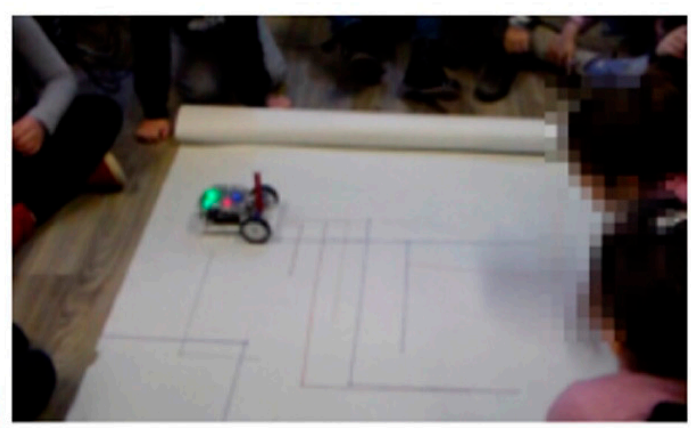

Figure 7. (a) A first grader programming of the GeomBot in the Scratch-based environment; (b) the GeomBot executing a programmed sequence.

The effective presence of the social dimension was highlighted by all the teachers of the group as they reported the experimental phase in their classes.

\subsection{Feature 6 (Aspect G). Positioning with Respect to Ethical Issues: The GeomBot's Inclusive Nature}

Mary, Sarah, Rita and Fiona mentioned an enhanced inclusiveness fostered in their classrooms by the GeomBot. This was an issue that arose during the final collective discussion as well. All classes of the nine teachers contained at least one student with special educational needs. Although we were not able to conduct case studies to investigate the learning processes of these students, the teachers commented on how the activities were easy to carry out in an inclusive setting and on how engaging they were generally for all students. A problem some teachers encountered was the lower attention levels of some students during the whole-class parts of some of the activities. Indeed, having only one GeomBot available in each classroom, with the students gathered on the floor around the GeomBot and in front of the computer screen projection where the programming occurred, led to a decrease in concentration of some students. This problem was solved by five of the teachers by having the class work in smaller groups at different learning stations and taking turns programming the GeomBot.

\subsection{Feature 7 (Aspect H). Positioning with Respect to the Role of Technology}

Teachers reported on a "cost" that comes with all the opportunities discussed: the time and energy that they must invest in becoming acquainted and at ease with the physical and digital aspects of the GeomBot. Almost all the teachers, including those who commonly use digital artifacts in their classrooms, mentioned feeling slightly frightened (unlike their students!) by the robot and by the Scratch-based programming environment: something might not work immediately and precious time that should be spent with the students might be wasted working through these issues; the robot might not perform as expected (initially some teachers did not recognize its behavior when the batteries were low); the surface on which the paper and the GeomBot are placed needs to be very flat, otherwise the drawings become less precise. Nevertheless, we note that this shared fear itself triggered some powerful 
forms of collaboration such as the ones we described in Section 3.4 Moreover, teachers quickly learned to deal with the practical and digital issues that arose, and they repeated during the concluding session how useful it was to collaborate with a teacher from the same school and "rehearse" before going to class, when this was possible.

\subsection{Answer to the Research Question}

Let us recall the research question guiding this study: how do teachers position themselves with respect to the educational space emerging from designing and implementing classroom activities with the GeomBot? In particular, what is the teachers' positioning with respect to the role of the GeomBot in fostering students' affective engagement, social interaction, cognition, geometrical knowledge and teaching practices?

The data we have collected shows that the Geombot intertwines digital and tangible modes of activity fostering the emergence of a rich socio-cultural environment where objectification and subjectification processes may occur. Based on the eight symbolic superstructures (Section 2.2.2, list from A to $\mathrm{H}$ ) that define the space where the teaching and learning of geometry take place, our analyses led to seven features that characterize the teachers' positioning with respect to the educational space involving mathematical practices with the GeomBot. The seven features cover the basic elements that amount to a significant and robust learning of mathematics: mathematical contents, language and languages, accepted teaching practices, problems and situations, conception of the student, forms of rationality, social interaction, ethics, technology. The teachers bring new possibilities of thinking and action that testify a change of perspective towards the teaching and learning of geometry.

\section{Discussion}

In this final section, we discuss the identified features to pinpoint how the GeomBot provides a unique combination of mathematics learning opportunities for students and teachers. In particular, we describe how the change in teachers' perspective allows for a fruitful implementation of the Geombot in students' objectification of geometry, testifying a dual nature of this physical programmable artifact in realizing a learning environment and allowing a critical positioning of the teachers.

A common denominator across the seven features that we identified is the multimodal nature of the drawing robot: indeed, the characteristics of the educational space and the subsequent teachers' positionings all pivot around this. The GeomBot intertwines tangible and digital modes of activities, thus realizing the entanglement of the ideal and the material that defines sensuous cognition. We believe that the intertwining of the tangible and the digital opened the way for the unfolding of the variety of features that allowed for a significant change in the teachers' identity during their action research experience with Geombot.

One aspect that was somewhat unexpected, but extremely important from our point of view, is the issue that emerged about how working with the GeomBot led to new mathematical considerations for the teachers, and therefore, very likely, to different mathematical learning of their students. For example, when discussing the activities that involved the GeomBot moving on a grid, the teachers noticed how the choice of making the GeomBot trace out its path starting from inside a square and moving from inside of one square to the next, was problematic: the $15 \mathrm{~cm}$ segments corresponding to one step almost never started or finished in the centers of the squares on the grid. Moreover, when counting the number of steps it took the GeomBot to finish its walk (and thus measure the length of the path) many students would get confused about whether they were counting "squares" (so "half squares" were necessary) or "steps". These considerations led the group to prefer making the GeomBot draw on the lines of the grid instead of inside the squares, and to modify the activities accordingly for future implementations. We find this choice to be coherent with higher level mathematics that involves, for example, coordinate systems and the Cartesian plane. Never before had the teachers thought of similar considerations, and they had never questioned positioning robots (like the Bee-bot) inside squares, as suggested by many common preschool and early primary school activities. Therefore, 
the GeomBot contributed to pushing the senses towards new forms of geometrical perception, developing them into theoreticians in the sense implied by the Theory of Objectification.

With respect to the notion of angle as rotation, we realized that perhaps the Geombot's design could be ameliorated, so that teachers would not feel the need to introduce additional artifacts such as the "fan" to guide students' learning. After carefully analyzing the difficulties encountered by the teachers in approaching this geometrical notion, the first author has changed the design of the GeomBot so that it holds a second marker in front of the caster. This allows for a double trace (potentially with markers of different colors) to be left by the GeomBot, which becomes particularly significant during rotations centered between the wheels: the "back" marker stays in one point, while the front marker draws an arc sweeping the rotation. This was the most significant feedback (together with the students' proposal of "GeomBot" as the name of the robot) leading to modifications to the robot's design. Future didactical experimentations will reveal the value of this change in the GeomBot's design.

A second mathematical consideration that emerged was the teachers' noticing and giving value to students' different ways of thinking; in particular they seemed to re-valuate "trial-and-error" strategies, which in other mathematical contexts are not valued by teachers. This reminded us of Turkle and Papert's [42] thoughts on different ways of thinking and their re-evaluation of what they referred to as the concrete "bricoleur's approach" that involves conversations with the machine, as opposed to the "planner's approach" which corresponds to a more abstract way of thinking that traditionally was considered more advanced. The teachers, however, also quickly noticed and praised the ways of thinking that they considered to be "more general", as we noted in "feature 2". These changes in what the teachers considered to be mathematically relevant (which also led them to engage in deep mathematical discussions during the meetings) and valuable in terms of mathematical thinking may have been fostered by the physicality of the GeomBot, which made the situations very "approachable" and less threatening both for them and for the children. Indeed, the forms of sensuous cognition fostered by the GeomBot seem to facilitate this phenomenon. This leads us to a second issue that uniquely characterizes learning with a digital tool that also has physical modes of mediation like the GeomBot. The emergence of the new mathematical learning opportunities mentioned above may also have been initiated by the strong and positive emotional response of the students and the teachers to the GeomBot, as described in "Feature 4". This affective dimension fostered by body syntonic and ego syntonic [7] characteristics of the GeomBot appears to be much stronger when compared to other digital tools such as dynamic geometry applets (see, for example, [37]). The GeomBot was referred to by the teachers, who picked up on their students' words, as something "alive" with human or animal-like features to whom students assign a gender (in most cases male, in some female). It would be interesting to see the students' behaviors in languages where there is a neutral form-like "it" in English—-to figure out whether there are differences.

A third issue, somewhat marginal in this paper, but extremely important from an educational perspective, is that of inclusiveness. Learning activities that involve friendly, moving robots are known in the literature for their great potential in providing more learning opportunities for students with different learning preferences or needs-e.g., $[15,16,43,44]$. Although this issue was mentioned in the "feature 5 " and noticed by the teachers, more research and dedicated studies are definitely necessary.

\section{Limitations and Directions for Future Research}

The small number of participants is surely a limitation to the generalizability of our findings; however, for this kind of qualitative research and the amount of data collected, it can be considered a satisfying sample number. We believe that the major limitation to generalizability of this study is the composition of the group of participants to the action research project. Indeed, the participants in our sample were relatively experienced both as teachers and as participants in action research projects offered within the GRSDM at the University of Pisa. An important difference that this might have made is the quality of the documental data collected within this project. Moreover, the teachers' experience 
in designing and experimenting with learning activities is likely to have positively influenced the quality of the activities themselves and of the identification of parts that needed to be ameliorated.

One direction to explore in future research is the extent to which the study can be empirically replicated. A second direction, that we are quite keen on, involves opening a dialogue between communities of educators who conduct research in mathematics education, like ourselves, and research in computer science education, respectively. At the moment there seems to be a very limited (if existent at all) dialogue between the communities and this seems to negatively impact most of the classroom activities that involve programming physical or digital robots.

\section{Patents}

Currently there is a patent pending on the GeomBot, request number 102019000018254, deposited 8th October 2019.

Author Contributions: Conceptualization, all authors; Methodology, A.E.B.-F., A.D.Z., G.S.; Software, E.F.; Design of the GeomBot, E.F., A.E.B.-F; Investigation and Resources, A.E.B.-F.; Writing-Original Draft Preparation, A.E.B.-F., A.D.Z., G.S.; Writing—Review \& Editing, all authors. All authors have read and agreed to the published version of the manuscript.

Funding: This research received no external funding.

Acknowledgments: We wish to acknowledge the active collaboration on the development of the motherboard and wireless communication between the laptop and the GeomBot of David Ferster, without whom this study would not have been possible. We also wish to thank the teachers of the GRSDM of the University of Pisa, who took part in this study.

Conflicts of Interest: The authors declare no conflict of interest.

\section{References}

1. Bartolini Bussi, M.G.; Mariotti, M.A. Semiotic mediation in the mathematics classroom. In Handbook of International Research in Mathematics Education, 2nd ed.; English, L., Kirshner, D., Eds.; Routledge: New York, NY, USA, 2008; pp. 746-783.

2. Arzarello, F. Semiosis as a multimodal process. Rev. Lat. Am. Investig. Mat. Educ. 2006, 9, 267-299.

3. Radford, L. The ethics of being and knowing: Towards a cultural theory of learning. In Semiotics in Mathematics Education: Epistemology, History, Classroom, and Culture; Radford, L., Schubring, G., Seeger, F., Eds.; Sense Publishers: Rotterdam, The Netherlands, 2008; pp. 215-234.

4. Radford, L.; Arzarello, F.; Edwards, L.; Sabena, C. The multimodal material mind. In First Compendium for Research in Mathematics Education; Cai, J., Ed.; NCTM: Reston, VA, USA, 2017; pp. 700-721.

5. Calmet, C.; Hirtzig, M.; Wilgenbus, D. 1,2,3...Codez! Enseigner L'informatique à L'école et au Collège; Editions Le Pommier: Paris, France, 2016.

6. Papert, S. Teaching Children Thinking. J. Struct. Learn. 1975, 4, 219-230. [CrossRef]

7. Papert, S. Mindstorms: Children, Computers, and Powerful Ideas; Basic Books: New York, NY, USA, 1980.

8. Clements, D.H. Longitudinal Study of the Effects of Logo Programming on Cognitive Abilities and Achievement. J. Educ. Comput. Res. 1987, 3, 73-94. [CrossRef]

9. Hoyles, C.; Sutherland, R. Logo Mathematics in the Classroom; Routledge: London, UK, 1989.

10. Hoyles, C.; Healy, L.; Sutherland, R. Patterns of discussion between pupil pairs in computer and non-computer environments. J. Comput. Assist. Learn. 1991, 7, 210-228. [CrossRef]

11. Hoyles, C.; Noss, R. Learning Mathematics and Logo; MIT Press: Cambridge, MA, USA, 1992.

12. Clements, D.H.; Meredith, J.S. Turtle Math; Logo Computer Systems: Montreal, QC, Canada, 1994.

13. Noss, R.; Hoyles, C. Windows on Mathematical Meanings; Kluwer Academic Publishers: Amsterdam, The Netherlands, 1996.

14. Clements, D.H.; Battista, M.T.; Sarama, J. Logo and Geometry. J. Res. Math. Educ. Monogr. Ser. 2001, 10. [CrossRef]

15. Atkinson, B. Learning disabled students and Logo. J. Learn. Disabil. 1984, 17, 500-501. [CrossRef] [PubMed]

16. Michayluk, J.O.; Saklofske, D.H. Logo and special education. Can. J. Spec. Educ. 1988, 4, 43-48. 
17. Highfield, K.; Mulligan, J.T. Young children's embodied action in problem-solving tasks using robotic toys. In Proceedings of the 33rd conference of the International Group for the Psychology of Mathematics Education, Thessaloniki, Greece, 19-24 July 2009; Tzekaki, M., Kaldrimidou, M., Sakonidis, H., Eds.; PME: Thessaloniki, Greece, 2009; Volume 2, pp. 273-280.

18. Highfield, K. Robotic toys as a catalyst for mathematical problem solving. Aust. Prim. Math. Classr. 2010, 15, 22-27.

19. Sinclair, N.; Baccaglini-Frank, A. Digital technologies in the early primary school classroom. In Handbook of International Research in Mathematics Education, 3rd ed.; English, L., Kirshner, D., Eds.; Taylor Francis; Routledge: New York, NY, USA, 2016; pp. 662-686.

20. Ronsivalle, G.B.; Boldi, A.; Gusella, V.; Inama, C.; Carta, S. How to implement educational robotics' programs in Italian schools: A brief guideline according to an instructional design point of view. Technol. Knowl. Learn. 2019, 24, 227-245. [CrossRef]

21. Bartolini Bussi, M.G.; Baccaglini-Frank, A. Geometry in early years: Sowing the seeds towards a mathematical definition of squares and rectangles. ZDM Math. Educ. 2015, 47, 391-405. [CrossRef]

22. Bartolini Bussi, M.G.; Baccaglini-Frank, A. Using pivot signs to reach an inclusive definition of squares and rectangles. In Proceedings of the 9th Congress of European Research in Mathematics Education (CERME 9); Krainer, K., Vondrová, N., Eds.; Charles University in Prague, Faculty of Education: Prague, Czech Republic, 2016; pp. 1891-1897.

23. Benton, L.; Hoyles, C.; Kalas, I.; Noss, R. Bridging Primary Programming and Mathematics: Some Findings of Design Research in England. Dig. Exp. Math. Educ. 2017, 3, 115-138. [CrossRef]

24. Cunningham, C.H. No, Engineering Isn't Just about Job Creation. Educ. Week Spotlight 2019, 7. Available online: https://www.edweek.org/ew/articles/2019/02/20/no-engineering-isnt-just-about-job-creation.html (accessed on 20 May 2019).

25. Corradini, I.; Lodi, M.; Nardelli, E. An investigation of Italian primary school teachers' view on coding and programming. In International Conference on Informatics in Schools: Situation, Evolution, and Perspectives; Pozdniakov, S.N., Dagienė, V., Eds.; Springer: Cham, Switzerland, 2018; pp. 228-243.

26. Reich-Stiebert, N.; Eyssel, F. Robots in the classroom: What teachers think about teaching and learning with education robots. In International Conference on Social Robotics; Agah, A., Cabibihan, J.-J., Howard, A.M., Salichs, M.A., He, H., Eds.; Springer: Cham, Switzerland, 2016; pp. 671-680.

27. Khanlari, A. Teachers' perceptions of the benefits and the challenges of integrating educational robots into primary/elementary curricula. Eur. J. Eng. Educ. 2016, 41, 320-330. [CrossRef]

28. Leont'ev, A.N. Activity, Consciousness and Personality; Prentice Hall: Englewood Cliffs, NJ, USA, 1978.

29. Leont'ev, A.N. Problems of the Development of the Mind; Progress: Moscow, Russia, 1981.

30. Radford, L. Gestures, Speech and the Sprouting of Signs: A Semiotic-Cultural Approach to students' Types of Generalization. Math. Think. Learn. 2003, 5, 37-70. [CrossRef]

31. Radford, L. Towards an embodied, cultural, and material conception of mathematics cognition. ZDM 2014, 46, 349-361. [CrossRef]

32. Radford, L. Sensed objects, sensing subjects: Embodiment from a dialectical materialist perspective. In The Body in Mathematics; Edwards, L., Krause, C., Eds.; Sense/Brill: Rotterdam, The Netherlands, in press.

33. Ferretti, F.; Gambini, A.; Santi, G. The Gestinv Database: A Tool for Enhancing Teachers Professional Development within a Community of Inquiry. In Proceedings of the Twenty-fifth ICMI Study School Teachers of Mathematics Working and Learning in Collaborative Groups; Borko, H., Potari, D., Eds.; University of Lisbon: Lisbon, Portugal, 2020; pp. 621-628.

34. Wenger, E. Communities of Practice: Learning, Meaning, and Identity; Cambridge University Press: Cambridge, UK, 1998.

35. Radford, L. Play and the production of subjectivities in preschool. In Mathematics education in the early years. Results from the POEM4 conference 2018; Carlsen, M., Erfjord, I., Hundeland, P.S., Eds.; Springer: Cham, Switzerland, 2020; pp. 43-60.

36. Cohen, L.; Manion, L.; Morrison, K. Research Methods in Education; Routledge: London, UK, 2007.

37. Baccaglini-Frank, A.; Di Martino, P.; Sinclair, N. Elementary school teachers' implementation of dynamic geometry using model lesson videos. In Proceedings of the 42nd Conference of the International Group for the Psychology of Mathematics Education; Bergqvist, E., Österholm, M., Granberg, C., Sumpter, L., Eds.; PME: Umeå, Sweden, 2018; Volume 2, pp. 99-106. 
38. Arzarello, A.; Bazzini, L.; Chiappini, G. A model for analyzing algebraic process of thinking. In Perspectives on School Algebra; Sutherland, R., Rojano, T., Bell, A., Eds.; Kluwer Academic Publisher: Dordrecht, The Netherlands, 2001; pp. 61-82.

39. Sfard, A.; Linchevski, L. The Gains and the Pitfalls of Reification: The Case of Algebra. Educ. Stud. Math. 1994, 26, 191-228. [CrossRef]

40. Duncker, K.; Lees, L. On problem solving. Psychol. Monogr. 1945, 58, 1-113. [CrossRef]

41. Smith, C.P.; King, B.; Hoyte, J. Learning angles through movement: Critical actions for developing understanding in an embodied activity. J. Math. Behav. 2014, 36, 95-108. [CrossRef]

42. Turkle, S.; Papert, S. Different ways people think: Epistemological pluralism and the revaluation of the concrete. J. Math. Behav. 1991, 11, 3-33.

43. Baccaglini-Frank, A.; Antonini, S.; Robotti, E.; Santi, G. Juggling reference frames in the microworld Mak-Trace: The case of a student with MLD. In Proceedings of the Joint Meeting of PME 38 and PME-NA 36; Nicol, C., Liljedahl, P., Oesterle, S., Allan, D., Eds.; PME: Vancouver, BC, Canada, 2014; Volume 2, pp. 81-88.

44. Daniela, L.; Lytras, M.D. Educational robotics for inclusive education. Technol. Knowl. Learn. 2019, 24, $219-225$. [CrossRef]

Publisher's Note: MDPI stays neutral with regard to jurisdictional claims in published maps and institutional affiliations.

(C) 2020 by the authors. Licensee MDPI, Basel, Switzerland. This article is an open access article distributed under the terms and conditions of the Creative Commons Attribution (CC BY) license (http://creativecommons.org/licenses/by/4.0/). 